DE DE GRUYTER

OPEN

DOI 10.1515/pesd-2015-0031

PESD, VOL. 9, no. 2, 2015

\title{
GEOSPATIAL TECHNOLOGY IN ENVIRONMENTAL IMPACT ASSESSMENTS - RETROSPECTIVE.
}

\section{Laxmi Goparaju ${ }^{1}$}

Key-words: Impact, geospatial, Mirzapur, dry deciduous thermal power plant.

\begin{abstract}
Environmental Impact Assessments are studies conducted to give us an insight into the various impacts caused by an upcoming industry or any developmental activity. It should address various social, economic and environmental issues ensuring that negative impacts are mitigated. In this context, geospatial technology has been used widely in recent times.

The present study wishes to bring forth certain discrepancies detected while analyzing an Environmental Impact Assessment study of a proposed thermal power plant in Mirzapur district of Uttar Pradesh, India. If proper analysis is not done then the impacts are under estimated or over estimated. Thus, a proper understanding of the area under study and various techniques of analyzing satellite remote sensing data is required to achieve successful impact assessments which lead us in the right direction.
\end{abstract}

\section{Introduction}

Environmental Impact Assessments are carried out to study the impacts prior to a proposed industrial unit and later to study and analyze the impacts. Changes in land use/Land cover, biodiversity, air and water are analysed and mitigation measures are suggested. Monitoring the environment in close proximity ensures sustainable management of ecosystems. It requires that changes be studied both spatially and temporally. In view of this, remote sensing offers better potential over traditional methods owing to the availability of satellite data at various resolutions and at regular intervals of time.

The satellite data needs to be analysed properly to achieve a specific target especially in the case of forests and vegetation. If not analysed in a proper manner

\footnotetext{
1 Vindhyan Ecology and Natural History Foundation, Mirzapur, Uttar Pradesh, India goparajulaxmi@yahoo.com
} 
then it will fail to detect the impacts and target would not be achieved providing highly misleading information.

There are various private companies which do the environmental impact assessments as required by various project proponents. In doing so, they miss out certain critical details which result in interpreting the impacts in a haphazard way. One such example was noted while analyzing the remote sensing analysis done by a private organization for Welspun Thermal Power Plant. This example can be studied can be quoted as an example as to how certain things are perceived due to lack of knowledge.

\section{Proposed Thermal Power Plant: Location}

Proposed 2X660MW super critical coal based thermal power plant at Village Dadri Khurd, Tehsil Mirzapur in Mirzapur district of Uttar Pradesh.

The prerequisite for any industrial unit to establish itself in an area is to study the existing land use and land cover. Thus, to study the land use/land cover pattern of the study area they used remote sensing data and GIS. Some facts were concealed and some were based on revenue map data. The following analysis compares the results of the two land use /land cover analysis done, one done by the project proponent and the other done by an NGO Vindhyan Ecology and Natural History Foundation, Mirzapur, Uttar Pradesh.

\section{Materials and Methods:}

Acquisition of satellite remote sensing data:

The first step in analyzing a satellite remote sensing data is the selection of proper scene and acquisition of satellite data. The scene must be free from cloud cover, especially in the study area where it needs to be analysed.

The data used by the project proponent is stated in EIA as follows:

"Indian Remote Sensing satellite IRS P6 LISS IV MX digital FCC (False Color Composite) of current vintage data at $5 \mathrm{~m}$. Spatial resolution has been used for preparation of Land use/ Land cover thematic map of present study area."

Other details regarding satellite data are not mentioned.

The details of IRS P6 LISS IV MX are stated as follows: (Source: IRS -P6 data user's manual NRSA).The LISS-IV camera is a multi-spectral high resolution camera with a spatial resolution of $5.8 \mathrm{~m}$ at nadir. This camera can be operated in two modes: Mono and Multi-spectral. In the multispectral mode, data is collected in three spectral bands viz, 0.52 to $0.59 \mathrm{~m}$ (Green (band 2), 0.62 to $0.68 \mathrm{~m}$ (Red (Band 3), 0.76 to $0.86 \mathrm{~m}$ (NIR (Band 4)) and a swath of $23.5 \mathrm{Km}$.

Satellite data acquired by Vindhyan Ecology and Natural History Foundation (VENHF) is as follows: Satellite data was obtained for the time period: 25 -112013, Path/Row is $142 / 43$ of Landsat OLI. 
United States Geological Survey (USGS) Environmental Resource Observation and Science Centre (EROS) archive was searched for the appropriate data implying cloud free data. Winter season was selected as the forest canopy is in good condition, since it is a dry tropical forest; phenology plays a significant role in analyzing forest area.

The Landsat OLI (25-11-2013) was also downloaded as geo-referenced file, each band separately later layer stacked, to produce a composite image converted into IMG format. The bands in this case were 11 and the bands used for analysis are NIR (5), Red (4), and green (3). Other details are Projection UTM, Zone 44; Spheroid, WGS 84; Datum, WGS 84. Figure 1 showing the false colour composite of the study area.

\section{Land use/Land cover classification:}

The project proponent mentions the analysis done as follows: (Page 57-60 of EIA)

(iii) INTERPRETATION OF SATELLITE IMAGE

Hybrid technique has been used i.e. visual interpretation and digital image processing for identification of different land use and vegetation cover classes based on spectral signature of geographic feature. Spectral signature represents various land use class. Image interpretation keys are developed based on image characteristics like color, tone, size, shape, texture, pattern, shadow, association etc, which enables interpretation of satellite images for ground feature.

(iv) GROUND TRUTH DATA COLLECTION

Ground data on geo-environmental components of the study area were collected for verification of information of the different features of the study areas, which are responsible for the occurrence of specific spectral reflectance behavioural patterns. The detailed information on agricultural practices; wastelands, mining, industrial area etc. were collected along with other land features. Ground truth has been carried out for verification of the ground features (esp. one in doubt) interpretation accuracy and reliability of remotely sensed data, which cannot be interpreted directly on satellite imagery.

Methodology adopted by VENHF is as follows:

\section{Satellite data analysis:}

The Landsat data of the year 2013 was subjected to supervised classification. The training sets were derived based on knowledge of field and published data. Other relevant thematic maps like village location have been derived from high resolution Geo Eye data in Google Earth. Other thematic layers like road, rail were downloaded from DIVA-GIS as Shape files. The image processing software used is ERDAS Imagine (version9.0; 2005). 
The training sets were given based on information of field and visual interpretation of satellite data. 4-6 training sets were given from different parts of the scene for each class and merged to form a single representative class. The function Image alarm was used to see the appropriateness and extent of the signature covered in the scene. Classification algorithm chosen was of maximum likelihood. The dataset was then subjected to accuracy assessment. The classified dataset was subjected to post classification smoothing using ' $3 \mathrm{X} 3$ ' filter to remove noise. Area statistics were computed and analyzed for each class (Lillisend and Keifer, 2004).

The thermal power plant boundary (as mentioned in project proponent's EIA).

Based on these points plant boundary was drawn as shape file in vector domain. Exact boundary shape cannot be drawn due to lack of knowledge. A buffer of $10 \mathrm{~km}$ radius was drawn from this point that is the plant boundary. An AOI (Area of Interest) layer was created using the above mentioned boundary coordinates. It was used to generate a subset of the plant area from the larger image of Land use/Land cover. These are the coordinates used by the project proponent.

$1.25^{\circ} 00^{\prime} 16.887^{\prime \prime} \mathrm{N}, 82^{\circ} 4029.204$ ' $\mathrm{E}$

2. $24^{\circ} 59^{\prime} 45.117^{\prime \prime} \mathrm{N}, 82^{\circ} 4103.728^{\prime \prime} \mathrm{E}$

3. $24^{\circ} 58^{\prime} 41.858^{\prime \prime} \mathrm{N}, 82^{\circ} 4023.802^{\prime \prime} \mathrm{E}$

4. $24^{\circ} 58^{\prime} 41.645^{\prime \prime} \mathrm{N}, 82^{\circ} 3950.425^{\prime \prime} \mathrm{E}$

5. $24^{\circ} 59^{\prime} 08.278^{\prime \prime} \mathrm{N}, 82^{\circ} 4000.404^{\prime \prime} \mathrm{E}$

$6.24^{\circ} 59^{\prime} 44.581$ 'N, $82^{\circ} 4000.552^{\prime} \mathrm{E}$

There is a minor difference in the area statistics, which is because VENHF doesn't have the exact plant boundary. The plant boundary was generated based on co-ordinates gives in EIA report and based on that is the buffer area. The difference is minor and can be neglected.

\section{Results and Discussion:}

The project proponent discusses the results (as stated in project proponents EIA)

\section{Results}

In the present study, both digital image processing and visual interpretation technique were applied to generate output of Land use / Land cover map of study area on 1: 50,000 scale. A standard False Colour Composite (FCC) image has also been generated on the same scale. The study area has been divided into the following major classes of land use for the purpose of computing the area.

Land use/Land Cover Classification System

"The present land use / land cover maps were prepared based on the classification system of National standards (pg 57-60."

3.3.3 Land use of the Buffer Zone 
The land use pattern for $10 \mathrm{~km}$ radius study area around the project area is shown in the table below: Table 1 (Table No. 3.2 in the EIA report)

LAND USE /LAND COVER DISTRIBUTION IN THE BUFFER ZONE

Above table depicts that the buffer zone is dominated by the Fallow land which is $28.47 \%$ of the total land area. $22.93 \%$ of the total area is dominated by the degraded forests. Scrub Land covers $16.36 \%$ of the total land area. Both Fallow Land and Scrub are neither productive in terms of their use nor appears to be of very much significance to the nearby villagers.

Analysis done by Vindhyan Ecology and Natural History Foundation (VENHF):

Land use /Land cover classification: Accuracy assessment was done for the classified dataset independently by generating 250 random points (ERDAS version $9.0,2005)$. These points were then allotted to the concerned forest cover category after confirmation from ground truth. The accuracy of land use /land cover obtained after supervised classification is $88.25 \%$. The land use and land cover categories were quiet distinct with little overlap and hence could be delineated with great precision (figure 2).

The analysis observes the following in the project site and $10 \mathrm{~km}$ buffer zone (Table 2):

1. Agriculture/Settlement/Fallow: According to VENHF analysis the Agriculture area covers $27.01 \%$ of the total. It can be observed well in false colour composite and can be delineated. It is observed as pink/magenta in colour and having some geometrical shapes like square, rectangle etc. with smooth to medium texture and regular to sub-regular outline. It does not occur as a single class, it is mixed in between with settlements and fallow area. Thus the buffer zone is dominated by this class.

2. Fallow/Urban/ settlement Vs Human Settlement: Human settlement as such cannot be delineated as a separate class. It is mixed among agriculture and Urban developed areas. They are scattered and where ever there is agriculture, there are settlements. Fallow land is slowly utilized for urban infrastructure and settlements to satisfy the needs of growing population. In false colour composite visible as cyan color, irregular in shape, in between urban and settlement.

3. Plantation/vegetation Vs Dense forest: Plantation or vegetation does not occur as an isolated category. In Madihan forests, plantation activity is been practiced since 1960's. (Upadhyay and Srivastava, 1980). Bamboo plantation in Danti Madihan and Bela are a part of forest activity which have increased the dense forest cover in this region. Dense forest canopy is greater than $40 \%$. Mostly mixed 
tree species are found. Bamboo occurs naturally and gives a mixed forest appearance. It is visible on FCC as dark, red tone, coarse medium texture and contiguous pattern and regular to irregular shape.

4. Degraded forest/Scrubland /Open wasteland Vs Open forest: Degraded forest/scrubland/open waste land all are representatives of forest area where the forest canopy is less than $20 \%$ and trees are mainly stunted, bushes and grasses. Wastelands are described as degraded lands which can be brought under vegetative cover (Chopra, 2011). The canopy cover in open forests observed was between 20 - 40\%. Certain openings inside dense forests formed due to disturbance. It was noticed on FCC as light red greenish color smooth medium texture, contiguous to noncontiguous pattern with irregular outline.

5. Water: includes all water bodies that are lakes, streams, ponds and rivers in the study area. They appear in all shades of light blue to black tone, smooth texture and irregular shape.

\section{Discussion:}

1. Wrong citation of satellite data resolution: $5 \mathrm{~m}$ spatial resolution instead of $5.8 \mathrm{~m}$.

2. Acquisition date of satellite data is not mentioned in the EIA report. Date is important because the project area lies amidst tropical dry deciduous forest. From March to May it is a leafless period. Conducting a study regarding forest would not be achieved since it would give an appearance of scrub as all trees (mainly mixed forest) would have shed their leaves. An appropriate season is from November to January wherein the Trees are in good phenological condition.

3. The project proponent has failed to produce a false colour composite, which is the basis of land use and land cover classification. Some features can be visually seen and interpreted from it. In fact interpretation keys for land use /land cover are prepared from false colour composite based on tone, texture shape and colour.

4. Ground truth data collection: the project proponent states that information on wastelands; agriculture, mining and industries were collected for verification. This area is dominated by agriculture and tropical dry deciduous forests and Bamboo plantation. No mining areas and no industrial unit exist in this area as of now.

5. The project proponent has not mentioned any accuracy results and the verification of classified data. They mention that the land use/land cover 
classification was followed as according to national standards, but fail to give further clarification. The standard which is required used for Land use/Land cover classification system and is widely followed is the one proposed by Anderson (1971). The minimum level of interpretation accuracy in the identification of land use and land cover categories from remote sensor data should be at least 85 percent.

6. The analysis done by project proponent (assumed to be between MarchMay, 2011; as they submitted the EIA) emphasizes that the study area is dominated by scrub and fallow land and that they are useless to the local residents and farmers. Whereas ecologically scrub and grasslands are very much significant in supporting a large number of medicinal herbs and also animals (mostly insects and reptiles) especially in the dry tropical deciduous forests. Whereas, the analysis done by VENHF concludes that the area is dominated by tropical dry deciduous forest and agriculture, forests have become patchy due to disturbance and anthropogenic pressure and thus need further protection.

\section{Conclusions}

The above study had emphasized the use of appropriate satellite data and proper image processing techniques to be incorporated in Environmental Impact Assessment. This would assist in identifying the negative impacts on land use/land cover and vegetation which would help the managers and regulators to come up with suitable measures to reduce the harmful impacts on the surrounding environment. The potential of satellite remote sensing and GIS when fully exploited to the best would help positively in decision making. Geospatial technology helps in monitoring the changes in natural resources holistically, temporally and spatially which is an advantage over traditional methods. It should be used efficiently for the welfare of mankind and nature.

Acknowledgements. The author is thankful to Mr. Debadityo Sinha and his team for ground truth analysis. I am grateful to landsat.usgs.gov, for Landsat satellite data used for analysis in the study and www.diva-gis.org for providing various GIS data.

\section{References}

Anderson, James R., (1971), Land use classification schemes used in selected recent geographic applications of remote sensing: Photogramm. Engin. 37:4:. 379-387.

Champion HG, Seth SK (1968). Forest types of India. Manager publications. GoI,India. 
Chopra, N.(2011). Land use /Land cover at various levels from different scales of Remote sensing data of southern part of Sonebhadra district of U.P. Intern. Jour. of Geomatics and Geoscien.2: 1.

ERDAS Imagine, 9.0 (2005). Leica Geosystems geospatial imaging, LLC. (1991-2005).

Final Environmental Impact Assessment Report (2013). for proposed 2X660MW Super critical Thermal power plant at Dadri Khurd,Mirzapur Uttar Pradesh.

IRS P6 data user's manual, National Remote Sensing Agency, Hyderabad. IRS/NRSA/NDC/HB-10/03.

Lillisend TM, Keifer R (2004). Remote sensing Image interpretation. John Wiley, New York.

Upadhayay MD, Srivasatava SCN (1980). Forest Working Plan East Mirzapur Forest Division, circle, Varanasi II from 1981-1991. State forest Department, Nainital, U.P.

*** www.diva-gis.org version 7.5.0.0.

\section{List of tables and figures:}

Table 1 - Land use/Land cover details as provided by Project Proponent

Table 2- The Land use/Land cover analysis as done by VENHF

Figure 1 - False colour composite of the study area (Landsat OLI,2013)

Figure 2 - Land use /Land cover map of $10 \mathrm{Km}$ buffer area around the proposed plant boundary.

Table 1 - Land use/Land cover details as provided by Project Proponent

\begin{tabular}{|l|l|l|l|}
\hline & WLSPN table for LULC & & \\
\hline S.No. & Land use /Land cover & Area (in ha) & $\%$ area \\
\hline 1 & water bodies & 489.4 & 1.2 \\
\hline 2 & crop land & 3837.21 & 9.43 \\
\hline 3 & fallow land & 11577.99 & 28.47 \\
\hline 4 & Plt/veg & 854.67 & 2.1 \\
\hline 5 & Human settlement & 353.18 & 0.87 \\
\hline 6 & scrub land & 6653.74 & 16.36 \\
\hline 7 & open wasteland & 2543.05 & 6.25 \\
\hline 8 & Degraded forest & 9327.58 & 22.93 \\
\hline 9 & Dense forest & 5037.32 & 12.39 \\
\hline & & 40674.14 & 100 \\
\hline
\end{tabular}


Table 2- The Land use/Land cover analysis as done by VENHF

\begin{tabular}{|c|l|l|l|}
\hline S.No. & Land Use/Land cover (2013) & \% area & Area in ha \\
\hline 1 & Agriculture/Settlement/Fallow & 27.01 & 11128.7 \\
\hline 2 & Fallow/Urban/Settlement & 11.11 & 4576.23 \\
\hline 3 & Open fallow & 29.47 & 12143.2 \\
\hline 4 & Water bodies & 1.13 & 467.19 \\
\hline 5 & Dense forest & 16.39 & 6752.43 \\
\hline 6 & Open forest & 14.90 & 6139.71 \\
\hline & & 100.00 & 41207.46 \\
\hline
\end{tabular}

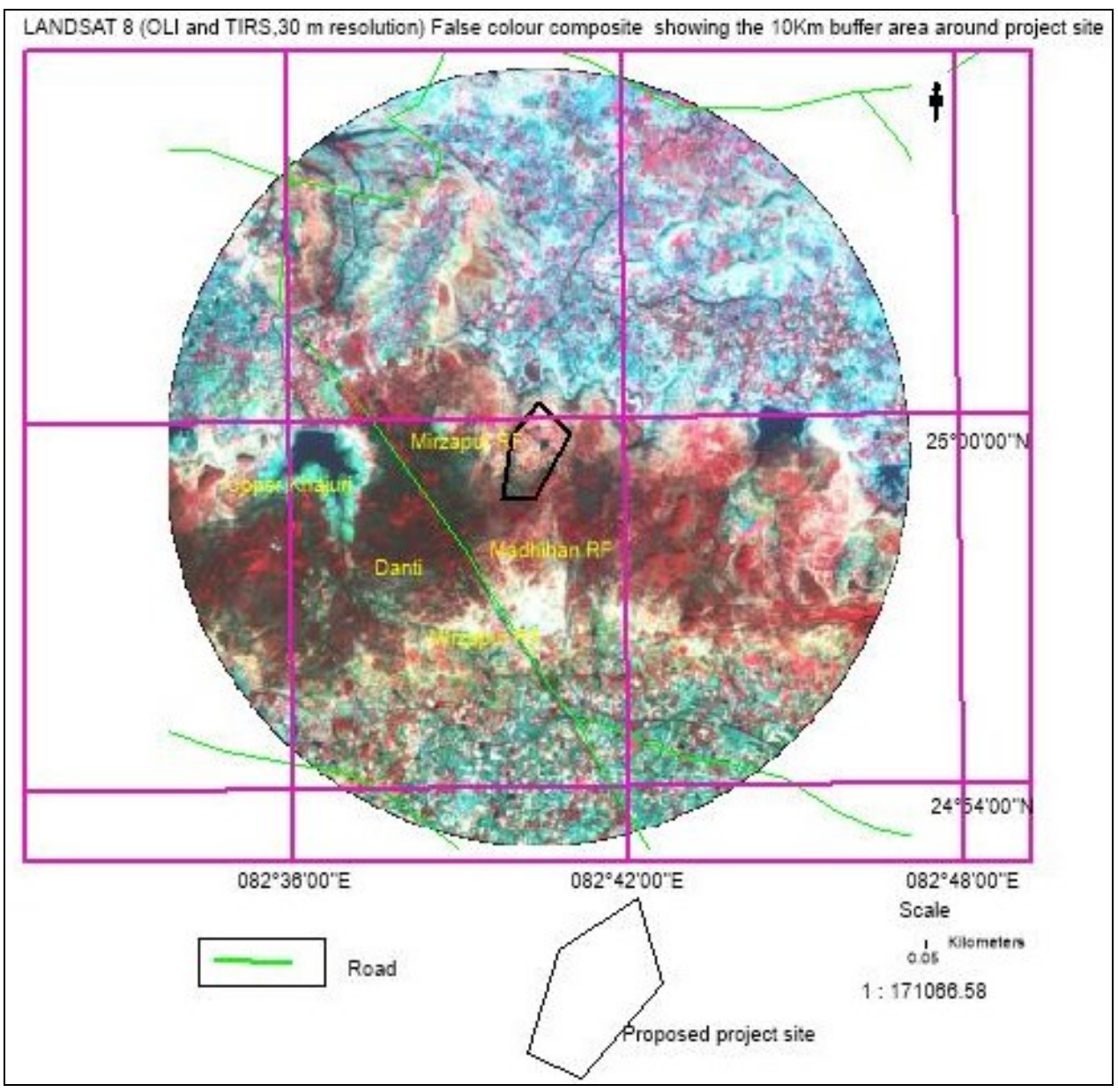

Figure 1 


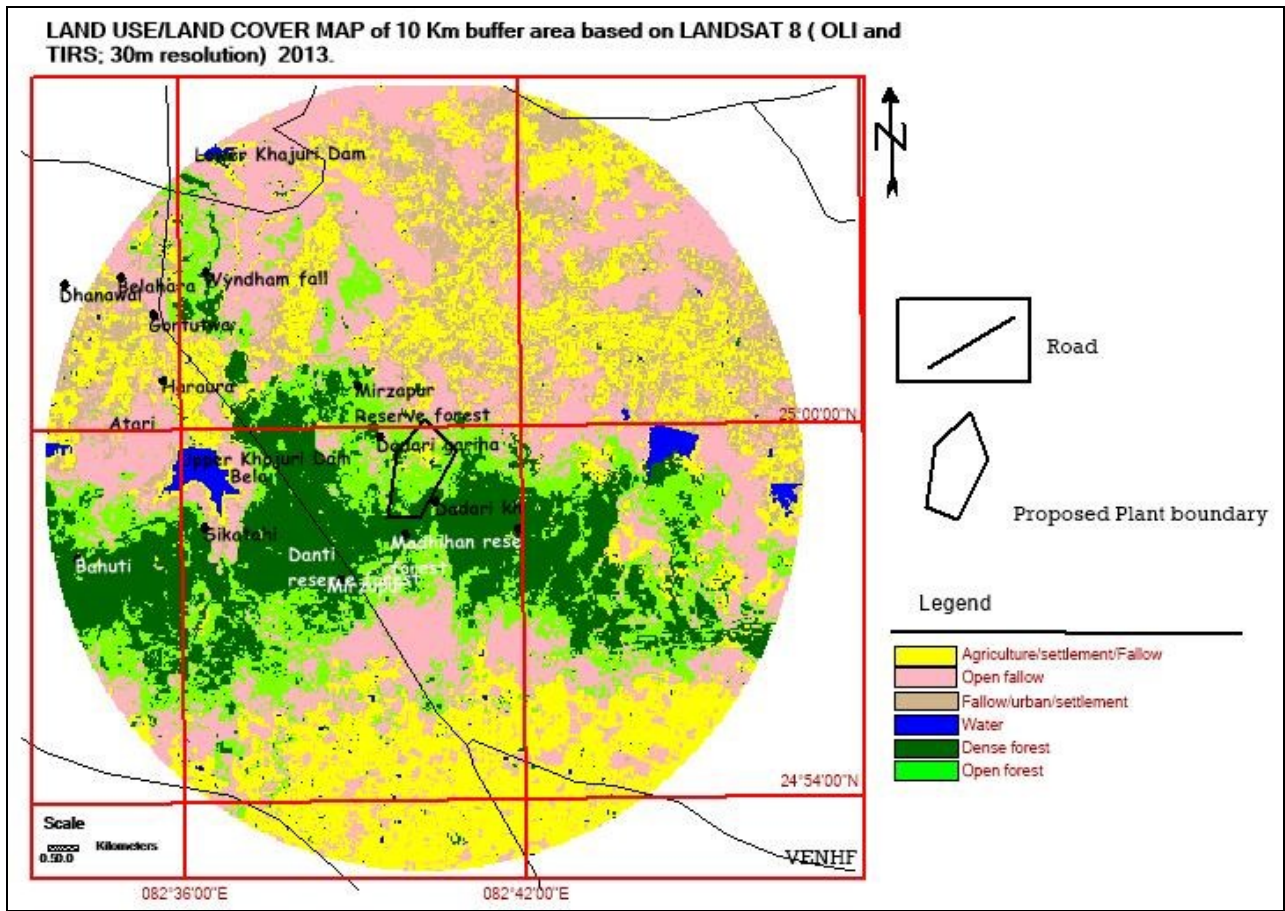

Figure 2 